\title{
Cristianismos en el idioma filosófico de las Enéadas de Plotino
}

En los diferentes sistemas de filosofía se puede observar siempre una arquitectura específica que determina la cohesión de los argumentos. Analizando el sistema, se puede hacer constar cuáles son las líneas fundamentales de su arquitectura y cuál la visión que domina el conjunto. Los textos hacen que nos preguntemos cuál es el ánimo del autor, el motor inmóvil que le hace optar por la específica visión del mundo que caracteriza el sistema en cuestión.

A continuación vamos a averiguar cuáles son los principios firmes y estables del sistema filosófico de las Enéadas que para su autor fueron evidentes por su propia fuerza, no resultando de argumentos teóricos. Entre los temas está el de la meditación interior, necesaria para el filósofo porque «encontrándote a ti mismo, encontrarás el fundamento y centro del universo»1. Esta invitación va acompañada de explicaciones acerca del camino que ha de seguirse y de una manera de ver distinta del modo de observación propio de nuestros sentidos ${ }^{2}$.

En la biografía de Plotino escrita por Porfirio encontramos una lista cronológica, cuidadosamente compuesta, de los 54 tratados de las Enéadas. Los tratados que inauguran la serie, llamados «tratados tempranos», ofrecen en muchos puntos el aspecto de una invitación a la meditación interior. Se trata de un tema sobre el que pone un énfasis especial; precisamente en estos primeros tratados, es el tema de la identidad fundamental del alma con el origen ${ }^{3}$.

El tratado que abre la lista cronológica (I 6 [1]) se presenta en su aspecto formal como una serie de variaciones sobre un tema de Platón. Este tema es la belleza según la teoría del Simposio, tal como la explica Sócrates por boca de Diótima (210 A - 212 B). La belleza se revela a nuestros sentidos en muchas formas que se parecen entre sí. El filósofo ha de comprender que

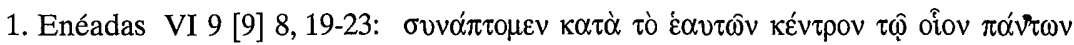

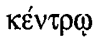

2. Enéadas I 6 [1] 8,25: ö $\psi i v \ddot{\alpha} \lambda \lambda \eta \eta v$

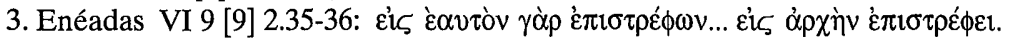


tanto en los cuerpos, como en nuestras actividades y conocimientos, se manifiesta la misma idea de belleza $(211 \mathrm{C})$. La belleza tiene sus grados. El filósofo empieza al sentirse cautivado por la belleza exterior de las cosas.observadas, y en un proceso de ascensión, llega a comprender que todas las cosas hermosas: virtudes, obras de arte, de conocimiento y de ciencia, participan en el mismo principio que es la idea o el eidos de lo bello. En esta ascensión filosófica aparecerá ante nuestros ojos una suprema idea: la belleza divina (Platon,

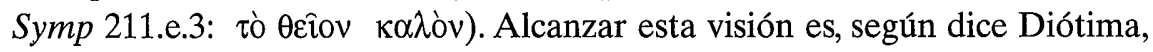
llegar a la meta y realizar el objeto de todos nuestros anhelos (Symp 211.b.7 :

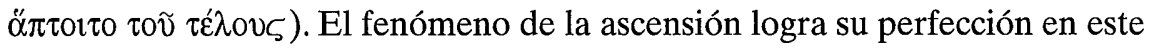
acto supremo del entendimiento filosófico.

En la teoría de Platón esta actividad del entendimiento es totalmente distinta de la descripción que ofrece Plotino del acto de contemplar el Uno que es el origen de todo lo que existe 4 .

La invitación a la vida interior se ofrece en I 6 [1] a base de un análisis de la identidad específica del alma. Cuando un alma, en vez de contemplar lo que ella debe contemplar, se llena de apetencias impuras, siguiendo sus experiencias corpóreas y hasta complaciéndose en su propia vergüenza ${ }^{5}$, tal impureza le sobreviene como una adición impropia ${ }^{6}$. La impropiedad añadida la deteriora y disminuye su vitalidad 7 . Así el alma cambia su propia identidad por otra ${ }^{8}$. La tarea que tiene ante sí consiste, por tanto, en restablecerse en su propio modo de ser, y esto quiere decir volver a su origen. Ha de purificarse de todo lo que le es ajeno para volver a ser lo que fue en su estado primordial. Como el oro cuando se acrisola, si el alma se despega de lo que le es extraño, estará sola consigo misma 9 . Para lograr ver lo que es un alma buena hace falta replegarse sobre uno mismo y adentrarse en la propia alma ${ }^{10}$, porque su centro se identifica con el centro y origen de todo el universo ${ }^{11}$.

Al grupo de los «tratados tempranos» pertenece también el tratado VI 9[9], que se mueve en la misma perspectiva que ya hemos observado en I 6 [1]. Dos son los puntos sobre los que recae el mayor énfasis: el centro del alma

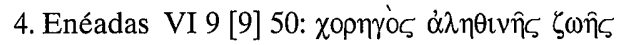

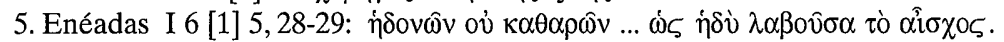

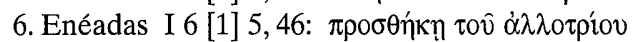

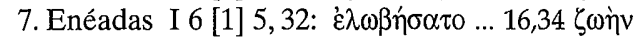

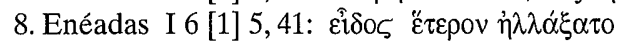

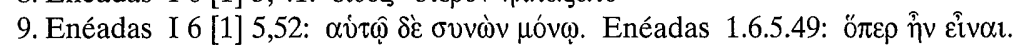

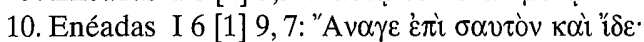

11. Enéadas VI 9 [9] 3, 20-22: '
}

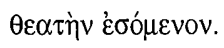


es idéntico al centro del universo ${ }^{12}$, y la necesidad de eliminar del alma todo lo que le sea ajeno y le haya sobrevenido en este mundo como una adición ( $\pi \rho \circ \sigma \eta \dot{n} \kappa \eta ̣$, véase la nota 6). Así el alma puede encontrarse consigo misma, distanciándose de todo lo que está fuera de su propia identidad, y convertirse hacia lo que está dentro ${ }^{13}$. El alma tiene que adentrarse en sí misma si quiere encontrar el camino que la conduzca a su propio origen. El que se conozca a sí mismo conocerá también su origen ${ }^{14}$. El origen no se halla fuera de nadie, sino que está presente en todos, aun sin saberlo ellos. No lo saben porque se evaden fuera de Él o, mejor dicho, fuera de sí mismos ${ }^{15}$. En este contexto encontramos la palabra «Padre» para indicar el primer origen, presente en todas las cosas. Es posible que el uso de este término lo haya tomado Plotino de los escritos de Valentín, dirigente de una escuela de gnosticismo y autor de muchos libros de mitología gnóstica. Valentín estuvo en relación con el cristianismo incipiente en Roma, donde desarrolló sus teorías en los años 136-166, y donde tuvo gran número de adeptos cristiano-gnósticos.

Ya en el primero, desde el punto de vista cronológico, de todos los tratados de las Enéadas encontramos la palabra Pater en la exhortación a la vida espiritual. El alma, liberándose de las ataduras del cuerpo que le obstaculizan el camino, tiene que huir de las tinieblas con las que se relaciona. Huyamos, pues, a nuestra patria querida. De esta patria hemos salido y en ella está nuestro Padre16.

¿Y cuál es este viaje y esta huida? Se impone renunciar al testimonio de nuestros ojos, y cambiar nuestra manera de ver por otra ${ }^{17}$ manera de ver que todos llevamos dentro y muy pocos la usan.

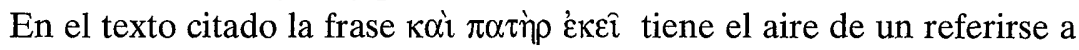
lo que ya saben las personas del auditorio; a la vez, es una transposición de la imagen mítica de la deidad Sofía como la presenta Valentín en su teoría sobre el pléroma divino. La perspectiva mitológica se ha transpuesto en la perspectiva metafísica del alma que anhela volver a su primer origen y primera unidad en la que se halla la raíz de su propia existencia. Sofía era, dentro del pléroma, la deidad más alejada del primer origen. Siente anhelo de volver a ese primer origen y, con gran riesgo personal, desea unirse a su Padre. En el gran

12. Véase nota 1.

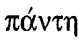

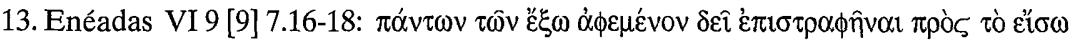

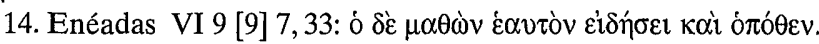

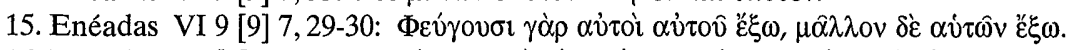

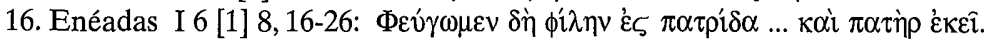

17. Enéadas I 6 [1] 8,25: ő $\psi 1 v$ ö $\lambda \lambda \eta v$ 
relato de Ireneo sobre el sistema mitológico de Valentín la historia es presentada como la historia de un enamoramiento ${ }^{18}$. Así la encontramos también en Enn. VI 9 [9]. Siguiendo su naturaleza, el alma se enamora de Dios y quiere unirse con él, como una virgen con amor noble se enamora de su Padre ${ }^{19}$. Descendiendo a través del universo, las almas se han enamorado de todo lo superfluo y adicional que acompaña a la vida. Ellas lo experimentan como si hubieran perdido parte de su propia constitución, desgarradas de la unidad original $^{20}$.

Esa situación de nostalgia de las almas se explica en el exordio de Enn. V 1 [10] en un contexto más bien dramático:

«Cuál puede ser el impulso que provoca a las almas a olvidarse de Dios su Padre y perder el conocimiento de sí mismas y de Él, aunque son partes de Él y a Él pertenecen enteramente?».

Cuando el alma llega a conocer su origen se hace verdad que le llega no en otro, sino en sí misma ${ }^{21}$, uniendo su propio centro con el centro del universo $^{22}$. Llegada a este punto, el alma vuelve a ser lo que fue ${ }^{23}$, lo que significa que ha completado el viaje ${ }^{24}$. Libre ya de todo lo que pertenece a la naturaleza corpórea y restablecida en su propia existencia, se encuentra en Dios

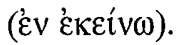

Llama la atención el énfasis que pone Plotino en sus tratados tempranos en los principios de meditación interior, tal como están formulados en I 6 [1] y VII 9 [9], y en la doctrina sobre el alma que subyace a estos principios, así como la frecuencia con que se repiten en todo el decurso de su obra. Esas declaraciones de principios acentúan la importancia que tenían para él. No parece una hipótesis aventurada suponer que esta preferencia por los principios de meditación interior le pudo haber llegado a Plotino de la enseñanza de su maestro Ammonio, en cuya escuela se había formado durante más de diez años, antes de poner por escrito sus primeros tratados. En su biografía de Plotino, nos cuenta Porfirio que, en la ciudad de Alejandría, había escuchado

18. Cfr. W.Völker, Quellen zur Geschichte der christlichen Gnosis, Tübingen 1932, 97 :

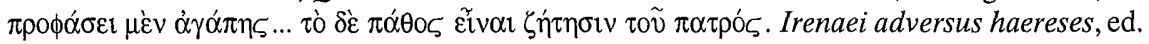
Harvey, Cantabrigiae 1857, tomus I.

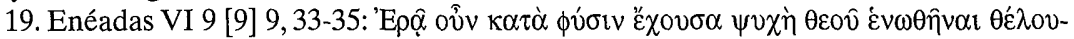

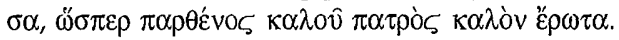

20. Enéadas V 1 [10] 1, 14: $\dot{\alpha} \pi \dot{p} p p \eta \xi \alpha \nu$

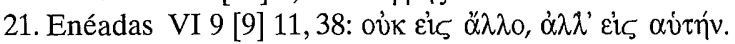

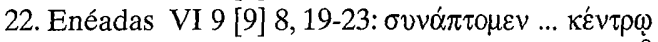

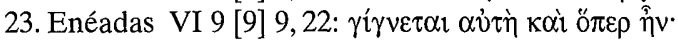
$\pi$ opeiaร».

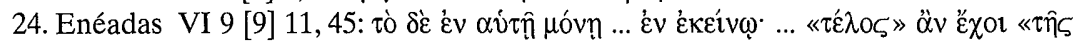


aquel las conferencias de toda una serie de profesores, sin mostrar particular interés, hasta que, por último, fue introducido en el aula de Ammonio, al salir de la cual dijo: «este es el hombre que yo estaba buscando» ( Evidentemente entre uno y otro había aflorado cierta afinidad espiritual. En el mismo capítulo Porfirio refiere que entre los discípulos de Ammonio existía el compromiso de no sustraer al secreto ninguna de las teorías de Ammonio. Añade, sin embargo, que Plotino, durante un período de diez años en que no escribió nada, daba sus conferencias de acuerdo con el espíritu de las enseñanzas de Ammonio.

DR. TH. G. SINNIGE Jeruzalem 8 $6881 \mathrm{JJ}$ Velp Holanda 